\title{
DIATREMES AND KIMBERLITES. 2: AN INTEGRATED MODEL OF THE ASCENT AND ERUPTION OF KIMBERLITIC MAGMAS AND THE PRODUCTION OF CRATER, DIATREME, AND HYPABYSSAL FACIES
}

\author{
Lionel Wilson $^{\mathbf{1}}$ and James W. Head ${ }^{2}$ \\ ${ }^{1}$ Lancaster University, U.K.; ${ }^{2}$ Brown University, U.S.A.
}

\section{INTRODUCTION}

We have summarized [Head and Wilson, 2003] the definitions and characteristics [see also Mitchell, 1986; Clement and Reid, 1989] of kimberlites and diatremes and assessed the major factors that need to be explained in any model for the formation of these features. These factors include: (1) lack of extensive extrusive deposits; (2) the lack of exposed plutonic complexes; (3) kimberlitic composition and mineralogy; (4) a tripartite division into crater, diatreme and hypabyssal regions and the distinctive facies associated with each of these; (5) the volatile-rich nature, dominantly carbon dioxide; (6) the implied low temperatures of emplacement; (7) the nature and distribution of country rock inclusions; (8) the nature and distribution of mantle xenoliths; (9) the presence of diamonds; (10) the presence of wide parts of the dikes; (11) the presence of "blows"; (12) the configuration of contemporaneous and internal dikes; (13) the general lack of subsequent dikes; (14) the apparent rapid emplacement; (15) the presence of olivine-cored pelletal lapilli surrounded by usually altered quenched kimberlitic melt or glass; (16) the paucity of thermal metamorphism; (17) the carrotshaped nature of the diatreme; (18) the presence of country-rock clasts typically devoid of a kimberlitic mantle; (19) the common absence of vesicles and composite lapilli; (20) the presence of glass and rapid quenching; (21) the pronounced sphericity of lapilli and their 1-10 $\mathrm{mm}$ size; (22) the presence of angular xenoliths from local rocks and smaller amounts of more rounded lower crustal and mantle material; and (23) the presence of country rock xenoliths from the uppermost part of the stratigraphic section exposed deeper within the diatreme.

\section{THE MODEL}

On the basis of these constraints and characteristics, we outline a model for the formation of diatremes as a result of eruptions of kimberlite magmas based on the availability of copious carbon dioxide in the mantle source. We suggest that essentially all of the rise to the surface takes place via propagation of a dike, which minimizes thermodynamic problems associated with transporting diamonds from mantle depths. Our model differs from that in [Anderson, 1979] in that the $\mathrm{CO}_{2}$ is present in the source and is progressively exsolved from the magma, rather than being acquired as the dike passes through a shallower $\mathrm{CO}_{2}$-rich layer.

Dike propagation is initiated when the percentage of partial melt in the source exceeds some critical level that allows upward drainage to begin at a rate so large that the maximum strain rate at which the matrix can deform plastically is exceeded. Magma in the tip of any propagating dike attempts to reach the lowest possible pressure in order to maximize the pressure gradient acting along the dike and hence to maximize the magma flow rate. As a result an initially small region below the tip exsolves $\mathrm{CO}_{2}$ fluid, the pressure in which is maintained as far as possible at the solubility limit of this volatile phase in the magma [Lister and Kerr, 1991; Rubin. 1993].

Consider a melt starting at a depth of $\sim 100 \mathrm{~km}$, where the pressure is $\sim 3 \mathrm{GPa}$. This melt could contain as much as 20 weight $\%$ of $\mathrm{CO}_{2}$; the pressure-dependent solubility of this volatile is such that the dike tip pressure would be buffered at $\sim 2 \mathrm{GPa}$. As the dike tip propagates upward, extensive fracturing of host rocks for a distance on either side of the dike roughly equal to its thickness should occur over most of the vertical extent of the dike. The pressure difference driving the dike magma (source pressure minus tip pressure) would be fixed at $1 \mathrm{GPa}$, and by the time the tip reached shallow depths the pressure gradient, although decreasing as the dike lengthened, will still be $\sim(1$ $\mathrm{GPa} / 100 \mathrm{~km}=) \sim 10,000 \mathrm{~Pa} / \mathrm{m}$, several times larger than the gradients driving basaltic eruptions from shallow magma reservoirs and leading to rise speeds of up to a few tens of $\mathrm{m} / \mathrm{s}$, the exact value depending on the magma viscosity.

As the dike tip rises, equilibrium volatile release into a vapor-filled cavity below the tip becomes ever less easy to maintain and a foam of $\mathrm{CO}_{2}$ fluid bubbles develops in a vertical zone which, as the tip nears the surface, will be at least a few km long. When the tip breaks the surface, the pressurized $\mathrm{CO}_{2}$ fluid escapes rapidly to the 
atmosphere and a dramatic pressure decrease occurs in the shallow part of the dike, imploding the already fractured dike walls and creating brecciated country rock around the dike. The wave of depressurization propagates into the magma, releasing more $\mathrm{CO}_{2}$, and fragmenting and cooling the magmatic liquid. Meanwhile the expanding and cooling gas is accelerating the resulting pyroclasts into and through the brecciated host rock in an upward wave of fluidization.

\section{STEPS IN THE ERUPTION SEQUENCE}

Using this basic concept of generation, ascent and eruption, we now outline the stages in the eruption sequence and describe the features that form during each stage.

\section{STAGE 1: CRACK TIP PROPAGATION OUT OF DEEP SOURCE REGION AND $\mathrm{CO}_{2}$ FLUID SEGREGATION:}

The low pressure region in the propagating dike tip produces copious quantities of supercritical fluid $\mathrm{CO}_{2}$ as the dike sets out from the mantle source; this segregates into and floods the propagating dike tip region. The supply of $\mathrm{CO}_{2}$ is constantly renewed by streaming of degassed magma to the sides of the dike as the dike grows both upward and laterally, exposing fresh undegassed magma in the dike center.

\section{STAGE 2: EQUILIBRIUM VOLATILE RELEASE AND WALL FRACTURING:}

Magma rise speeds are likely to be at least a few 10s of meters per second when the dike tip is deep but will decrease progressively as the tip ascends and the overall pressure gradient driving the magma decreases. The dike tip pressure is buffered at $\sim 2 \mathrm{GPa}$ during the entire rise to the surface but the external pressure decreases due to the decreasing overburden. Wall rocks adjacent to the propagating dike tip region are fractured. Country rock is torn from the walls to become xenoliths, and quickly sinks through the $\mathrm{CO}_{2}$ fluid to become engulfed by and incorporated into the underlying magma.

The pressure difference across the dike walls increases toward shallower depths and thus the stresses and wall rock damage will be greater, but the geometry of dike emplacement means that there is no place for the fractured wall rock material to go after the dike tip passes unless it is plucked from walls by ensuing flow of magma. The relative abundance of xenoliths produced by wall rock fracturing will be a function of rock strength and position in the crust relative to the evolving differential stress; the most important factor will be the elapsed time that the wall rocks are exposed to dike emplacement, favoring deep xenoliths.

\section{StAGE 3: DIKE TIP NEARS THE SURFACE, DISEQUILIBRIUM PRODUCES MAGMATIC $\mathrm{CO}_{2}$ FOAM:}

As the dike tip nears the surface, there is continued compression and fracturing of the walls, and the possibility of intrusion of small dikelets due to the decreasing overburden pressure. The continuous increase in the vertical length of the $\mathrm{CO}_{2}$-fluid zone eventually produces disequilibrium conditions such that newly nucleating bubbles of $\mathrm{CO}_{2}$ fluid cannot make contact with the pocket of $\mathrm{CO}_{2}$ fluid in the dike tip, and so soon the upper part of the magma below the dike tip fluid cavity becomes a foam in which $\mathrm{CO}_{2}$ bubbles are dispersed in the magmatic liquid [Lister and Kerr, 1991; Rubin, 1993]. By the time the dike tip gets within $\sim 10 \mathrm{~km}$ of the surface the combined vertical length of these two zones is several kilometers. A second consequence of the disequilibrium is a lengthening of the vapor-rich zone and a decrease in the vapor pressure, perhaps by at least a factor of two.

\section{STAGE 4: DIKE TIP BREAKS SURFACE, VENTS GAS, IMPLODES WALLS:}

The propagating dike tip is convex upward and first reaches the surface at its highest central point, immediately starting to vent the upper $\mathrm{CO}_{2}$ vapor slug in the dike. Upon being exposed to the surface, the gas velocity increases from the $\sim 20 \mathrm{~m} / \mathrm{s}$ rise speed of the dike to $\sim 300 \mathrm{~m} / \mathrm{s}$ speed which results from the decompression of the vapor to atmospheric pressure, producing a classic Prandtl jet into the atmosphere. The dike will rapidly centralize along the widest portion (almost certainly the central part that reaches the surface first and within which the rise speed of magma and gas is greatest) and the remainder of the upper part of the gas-filled dike will rapidly close. This produces a linear fractured and crushed zone with little to no evidence of associated magma, in the center of which is a much more equant central vent. Within this vent, the break-through and the ensuing gas jet will rip wall rock from the uppermost country rock, and the proportion of shallow country rock should be high in the initial rim deposits. Some of the magmatic foam may also begin to vent at this time. Simultaneously, the sharp decrease in pressure caused by the gas venting implodes the walls of the upper part of the dike. 
STAGE 5A: DEPRESSURIZATION WAVE PROPAGATES DOWN INTO MAGMA :

At this point, the depressurization wave caused by the gas venting propagates back down into the magma and more $\mathrm{CO}_{2}$ is released in the magma-filled portion of the dike, forming additional foam during gas expansion. This expansion causes fragmentation of the magma while at the same time cooling it considerably.

$\mathrm{CO}_{2}$ gas expansion starting at these pressure and temperature conditions would have the following consequences: (1) gas expansion would be dramatic, creating a disrupting foam with much greater than half the available space being gas; (2) the intervening magma would fragment and surface tension would form the resulting liquid fragments into spheres to optimize surface area to volume; (3) spheres would tend to nucleate around any solid particles in the rising magma (olivine phenocrysts, xenolithic grains); (4) very rapid adiabatic cooling of these particles would occur to produce glassy or microcrystalline spherules, cored by phenocrysts and xenoliths; (5) cooling would be so rapid (going from magmatic to room temperature in seconds) that welding of particles and agglutinization would be uncommon.

\section{STAGE 5B: GAS EXPANSION CREATES UPWARD FLUIDIZATION WAVE, ACCELERATES CHILLED PYROCLASTS:}

The gas expansion in the dike caused by the gas venting accelerates the gas into the shattered country rock and produces an upward wave of fluidization that is the major cause of the formation of the diatreme structure. The combination of foam disintegration in the upper part of the dike below the gas phase, and the further foam formation and disintegration in the magma below the initial magmatic foam zone, is responsible for the upward fluidization wave. This produces a cold stream of gas through the upper part of the zone, which contains cooled spherules and fine-grained magmatic particles which migrate through the upper fractured zone and vent to the surface.

Variations in pressure will cause instabilities in the gas exsolution process and gas flow speed and this will introduce waves of gas release, pressure changes and venting. This will create a series of fluidization waves (a 'ringing') that may last several tens of minutes. During this time, continual readjustments in the diatreme will be taking place as compression and decompression waves propagate back and forth, and particle-containing cool gas flow permeates the diatreme zone and vents to the surface. This fluidization will cause sorting in the brecciated diatreme zone and settling of some of the country rock from the upper part of the column down into deeper parts of the diatreme. The disruption phase will also serve to modify, distort and destroy evidence of earlier stages of dike emplacement.

During this time, the magma deeper in the dike itself will quickly undergo catastrophic chilling and thus will cease to rise into the diatreme. The deposits on the surface should be characterized by a basal coarse breccia from the initial venting, followed by coarse fragments, xenoliths and lapilli from the initial magmatic foam phase, followed by deposits dominated by products from the second magmatic foam phase (chilled glass lapilli and ash). Rise of magma into the vent and subsequent ponding or flows are not predicted to be common.

\section{STAGE 6: EVENT AFTERMATH:}

Following the event, the deposits will be characterized by a porous cone-shaped diatreme surrounded by a crater rim of breccia and pyroclastic deposits. If the diatreme forms in an active groundwater area, a crater lake is likely to form and groundwater will permeate the diatreme, quickly altering the primary mineralogy. Although the surface deposits are similar in some ways to those of tuff cones and maars formed by hydrovolcanic processes, no part of this model requires interaction of the rising dike with groundwater. Such an interaction could happen, but the very rapid chilling of the magmatic foams minimizes the likelihood of prolonged and repetitive hydrovolcanic eruptions occurring during formation of diatremes.

\section{CONCLUSIONS}

This model for the ascent and eruption of kimberlitic magma accounts for the major observational characteristics of kimberlites and diatremes as outlined in [Mitchell, 1986; Clement and Reid, 1989] and summarized in the introduction. Cases in which abundant $\mathrm{CO}_{2}$ was lacking in deep melt sources could result in kimberlite dike intrusions and eruptions without diatreme formation, more similar to traditional basaltic pyroclastic eruptions.

\section{REFERENCES}

Anderson, O.L., 1979. The role of fracture dynamics in kimberlite pipe formation. In Boyd, F.R., and Meyer, 
H.O.A., eds., Kimberlites, Diatremes, and Diamonds. Their Geology, Petrology, and Geochemistry. Proc. 2nd Intl. Kimberlite Conf., v. 1. AGU, Washington, D.C., p. 344-353.

Clement, C.R., Reid, A.M., 1989. The origin of kimberlite pipes: An interpretation based on $\mathrm{s}$ synthesis of geological features displayed by southern African occurrences. Proc. Fourth Int. Conf. Kimberlites and Related Rocks, Perth, pp. 632-646.

Head, J.W., Wilson, L., 2003. Diatremes and kimberlites 1: Definition, geological characteristics and associations.. This volume.

Lister, J.R., Kerr, R.C., 1991. Fluid-mechanical models of crack propagation and their application to magma transport in dykes. J. Geophys. Res., 96, 10,04910,077 .

Mitchell, R.H., 1986. Kimberlites. Plenum Press, New York.

Rubin, A.M., 1993. Dikes vs. diapirs in viscoelastic rock. Earth Planet. Sci. Lett., 119, 641-659.

Contact: L Wilson, Environmental Science Dept., Lancaster University, Lancaster LA1 4YQ, U.K., E-mail: l.wilson@lancaster.ac.uk 